\title{
Solar Two
}

Solar Two proves the technology is in place for producing utility-scale power from the sun when you need it - during periods of peak electricity demand by consumers.

Solar Two is a concentrating solar power plant that can supply electric power "on demand" to the local utility, Southern California Edison Company. It can do so because it operates not only during sunny parts of the day, but it can store enough thermal energy from the sun to operate during cloudy periods and after dark, for up to three hours, at its rated output of 10 megawatts (MW). For the first time ever, a utility-scale solar power plant can supply electricity when the utility needs it most, to satisfy the energy requirements of its customers.

Located near Barstow, California, this power tower demonstration project is sponsored by the Solar Two Consortium, whose members are listed on p. 2, in partnership with the U.S. Department of Energy (DOE).

\section{Technical Achievement}

Solar Two represents a major technical achievement. The design is based on lessons learned at Solar One, this country's first power tower. Solar One operated as a pilot plant from 1982 to 1988 and proved that power towers can reliably produce electricity.

Solar One used water as a working fluid to generate the steam required to drive a conventional turbine. Project engineers calculated the power tower would operate more efficiently if it used a working fluid that could absorb and store thermal energy effectively. Molten salt was chosen as the preferred heat-storage medium because of its superior physical properties. The same substance used in nitrogen fertilizers, the salt for Solar Two is safe and environmentally benign.

\section{Operation}

As Solar Two operates, 2000 heliostats sun-tracking mirrors - reflect sunlight onto a receiver located at the top of a 300-foot tower. A digital control system focuses the heliostats

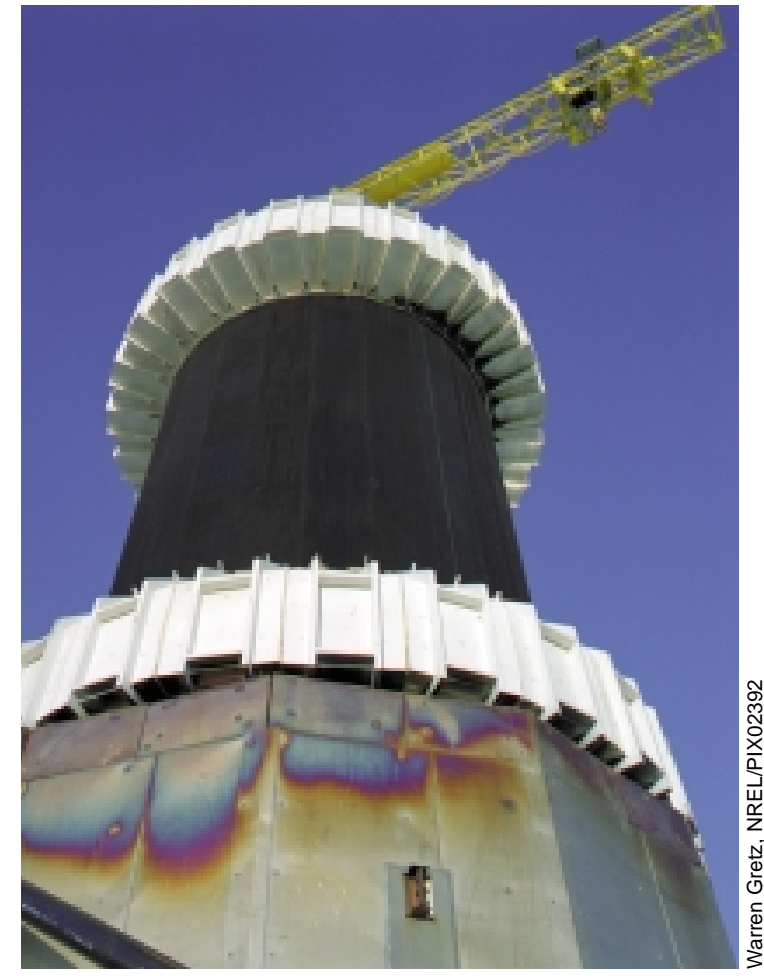

Research and development of more reliable and efficient receivers will continue as Solar Two's technology approaches commercial use.

precisely on the receiver as they track the sun across the sky, and the sunlight is concentrated up to 800 times its normal intensity.

The receiver is built using hundreds of vertical tubes; concentrated sunlight heats the molten salt as it flows through them. The salt reaches temperatures as high as $565^{\circ} \mathrm{C}$ $\left(1050^{\circ} \mathrm{F}\right)$, then it flows to the base of the tower where it is stored in a "hot" tank. When power production is needed, hot salt is pumped from the hot tank to generate steam, and electricity is produced by a conventional steam turbine. After the molten salt has cooled to about $285^{\circ} \mathrm{C}$ $\left(550^{\circ} \mathrm{F}\right)$ in producing the steam, it is again pumped to the top of the tower to be heated; and the cycle continues. 
To reduce construction costs, several large components from Solar One were used in Solar Two, including the tower, the original field of heliostats, and the turbinegenerator.

\section{Current Activities}

Solar Two was inaugurated in June 1996 and is scheduled to produce power through 1999. During this time, Solar Two will undergo continuous testing and evaluation. By testing Solar Two in a power production setting, engineers can increase confidence in the reliability and cost of future commercial power towers. Increased data on operating costs will be critical in convincing potential users to install this technology.

Several members of the Solar Two Consortium, including Bechtel Corporation and Rocketdyne Division of Boeing North American, are exploring commercial prospects for power towers. Using the experience of

\section{The Solar Two Consortium}

These Companies and Agencies Made it Possible:

\section{Consortium Participants}

Arizona Public Service Company

Bechtel Corporation

\section{California Energy Commission}

Electric Power Research Institute

Idaho Power Company

Los Angeles Department of Water and Power

\section{PacifiCorp}

Sacramento Municipal Utility District Salt River Project

Southern California Edison Company

\section{Contributors}

ABB Lummus

Chilean Nitrate

Gould Pumps

General Process Controls

Pitt-Des Moines

Raychem Corporation

Rocketdyne Division of Boeing North American

\section{Government Partners}

U.S. Department of Energy

Sandia National Laboratories

National Renewable Energy Laboratory
Washington, DC

Albuquerque, New Mexico

Golden, Colorado

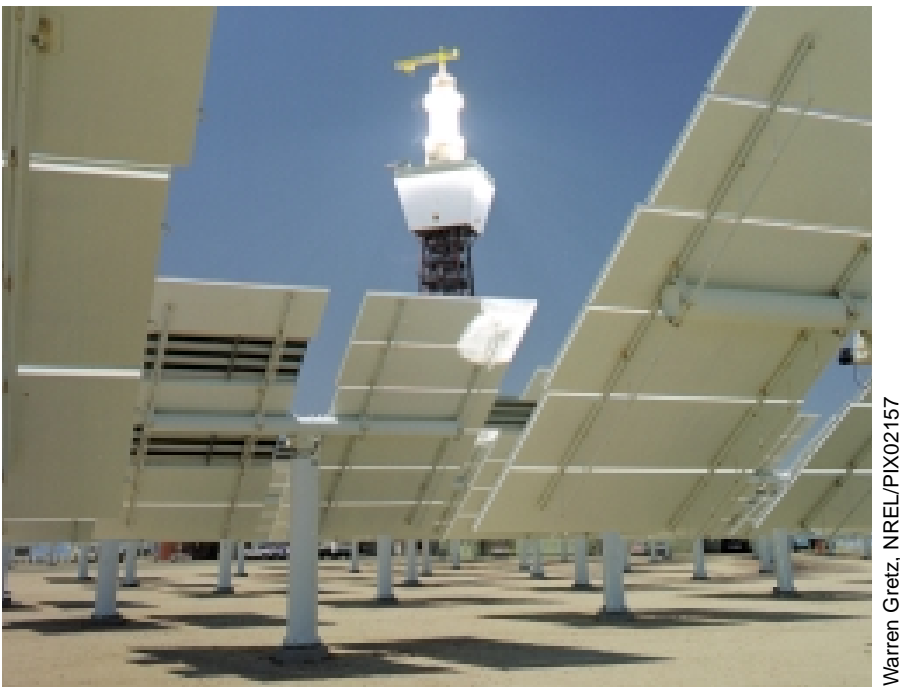

Supplying $10 \mathrm{MW}$ - enough to power 10,000 homes - to Southern California Edison Company's electric distribution grid during periods of peak demand, Solar Two is proving the value and technical capability of power towers.

Solar Two, U.S. industry can position itself to take advantage of what DOE and the International Energy Agency predict will become a multibillion dollar market for power towers during the next 10 to 20 years.
For on-line information about the U.S. Department of Energy's Concentrating Solar Power Program, please visit its web site: http://www.eren.doe.gov/sunlab

For more information on renewable energy or for additional copies of this brochure, contact the Energy Efficiency and Renewable Energy Clearinghouse (EREC): 1-800-DOE-EREC (363-3732)

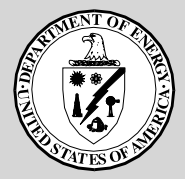

Produced for the

U.S. Department of Energy (DOE) 1000 Independence Avenue, S.W.

Washington, DC 20585-0121

Produced by Sun•Lab:

Bringing together solar energy expertise from Sandia National Laboratories and the National Renewable Energy Laboratory, DOE national laboratories.

DOE / GO-10098-562 April 1998 